\title{
A Summary of Results From the First NIMBUS 7 SMMR Observations
}

\author{
P. Gloersen, ${ }^{1}$ D. J. Cavalieri, ${ }^{1}$ A. T. C. Chang, ${ }^{2}$ \\ T. T. Wilheit, ${ }^{1}$ W. J. Campbell, ${ }^{3}$ O. M. Johannessen, ${ }^{4}$ \\ K. B. Katsaros, ${ }^{5}$ K. F. Kunzi, ${ }^{6}$ D. B. Ross, ${ }^{7}$ D. Staelin, ${ }^{8}$ \\ E. P. L. Windsor, ${ }^{9}$ F. T. Barath ${ }^{10}$ P. GUDMANDSEN,${ }^{11}$ \\ E. LANGHAM, ${ }^{12}$ AND R. O. RAMSEIER ${ }^{13}$
}

\begin{abstract}
Selected data obtained during the first year of operation of the scanning multichannel microwave radiometer (SMMR) on board the NIMBUS 7 satellite (launched in late October 1978) have been used to calculate, on a global basis, various geophysical parameters over open oceans, polar regions, and terrain. Over open oceans these calculations have provided values for sea surface temperatures, near-surface winds, atmospheric water vapor in a column, and rainfall rates. In polar regions, sea ice concentration, multiyear ice fraction, and radiating temperatures have been obtained. Finally, the extent and water equivalence of snow cover over terrain have been calculated. These parameters have been compared with in situ measurements of the same geophysical parameters, where available, and the results of these comparisons are described. The self-consistency of the global displays of all the parameters is discussed along with the plans for archiving them for subsequent research purposes. A description of the SMMR calibration and data processing scheme is also given.
\end{abstract}

\section{INTRODUCTION}

This paper describes some early results from the scanning multichannel microwave radiometer (SMMR) on board the NIMBUS 7 satellite, which was launched on October 24, 1978. The authors are members of the NIMBUS 7 SMMR Experiment Team (SMMR/NET) who were originally selected from respondents to a NASA Announcement of Opportunity; the first author is the chairman of that team. The SMMR/NET was chartered to develop applications for the SMMR data, to oversee instrument calibration and operation, and to determine the validity of the interpretations of the data in preparation for archiving the results. Since then, some additional members were elected to the team by the other members in recognition of significant contributions to the development of SMMR data applications. This paper is a response to that charter; we discuss improvements upon prelaunch versions of the algorithms used to yield estimates of the various geophysical properties from the observed radiances. We also discuss the validity of the input data from the standpoints of proper earth location and calibration. The geophysical properties re-

\footnotetext{
${ }^{1}$ Goddard Laboratory for Atmospheric Sciences, NASA/Goddard Space Flight Center.

${ }^{2}$ Earth Survey Applications Division, NASA/Goddard Space Flight Center.

${ }^{3}$ USGS Ice Dynamics Project, University of Puget Sound.

${ }^{4}$ Geophysical Institute, University of Bergen.

${ }^{5}$ Department of Atmospheric Sciences, University of Washington.

${ }^{6}$ University of Bern.

${ }^{7}$ NOAA Sea-Air Interaction Laboratory.

${ }^{B}$ Research Laboratory of Electronics, Massachusetts Institute of Technology.

${ }^{9}$ Dynamics Group, British Aerospace.

${ }^{10}$ California Institute of Technology, Jet Propulsion Laboratory.

11 Electromagnetics Institute, Technical University of Denmark.

12 RADARSAT Project Office.

${ }^{13}$ Atmospheric Environment Service.
}

This paper is not subject to U.S. copyright. Published in 1984 by the American Geophysical Union.

Paper number 3C1583. ferred to include nearly all-weather observations of sea surface temperatures, near-surface winds over the oceans, water vapor over oceans, sea ice concentration, sea ice age, sea ice radiating temperature, and snow cover over terrain. In this paper we describe current production algorithms, processing plans, conclusions from various investigations of the first-year data, and problem areas.

\section{INSTRUMENT DESCRIPTION}

The conceptual design for the SMMR for Nimbus 7 was developed at Goddard Space Flight Center, based on ideas originated by C. R. Laughlin and K. Richter; it was subsequently adapted for use also on the SEASAT A satellite. A team led by J. Johnston did the final design and fabrication at the Jet Propulsion Laboratory.

The SMMR is a 10-channel instrument receiving both horizontal and vertical polarizations at wavelengths of $0.81,1.4$, $1.7,2.8$ and $4.6 \mathrm{~cm}$ and has been described in detail elsewhere [Gloersen and Barath, 1977]. Microwave radiation from the earth and its atmosphere is collected by an off-axis parabolic reflector and is directed into a multifrequency receiving horn which distributes the various radiometric components to appropriate radiometers. Scanning is accomplished by oscillating the parabolic reflector about a vertical axis between local azimuth angles of $+25^{\circ}$ and $-25^{\circ}$ with a period of $4.096 \mathrm{~s}$. The various integrate-and-dump times of the radiometers combined with the oval instantaneous fields of view result in roughly circular beam spots ranging in diameter from about $30 \mathrm{~km}$ at $0.81 \mathrm{~cm}$ to $150 \mathrm{~km}$ at $4.6 \mathrm{~cm}$. Cross-track/alongtrack sampling intervals range from about $14 \times 14 \mathrm{~km}$ to $56 \times 28 \mathrm{~km}$ over that wavelength interval. The incoming microwave beam is at a constant angle of $42^{\circ}$ from nadir, corresponding to an earth incidence angle of $50.2^{\circ}$ at the Nimbus 7 orbital altitude of $955 \mathrm{~km}$. The SMMR scanning arrangement results in a conic intersection of the oscillating optic axis with the surface of the earth. The swath of the observations along the suborbital track is about $780 \mathrm{~km}$.

The SMMR consists of six separate radiometers, one for each wavelength, except $0.81 \mathrm{~cm}$, for which there is one for each polarization. Horizontal and vertical polarizations are observed on alternate scans at the four longest wavelengths 
and on each scan at the $0.81-\mathrm{cm}$ wavelength. In order to provide reference signals for gain variation adjustments in the data processing, small microwave receiving horns are aimed into space for low-radiance references. Ambient temperature waveguide terminations provide high-radiance references for each radiometer. The reference signals are switched into the radiometric data stream alternately at each extreme of the scan.

The oscillating reflector feeds a single fixed multispectral receiving horn, causing the orthogonal polarization components of the incoming radiation to rotate with respect to the polarization axes of the SMMR. Polarization mixing, therefore, occurs increasingly toward the ends of each scan and must be compensated for during data processing.

\section{Data Processing Scheme}

A number of steps are used in producing calculated values for the geophysical parameters from SMMR radiances. First, raw SMMR data are taken from the master data tapes in IBM user format output (UFO) tapes. These data are normalized with the internal gain monitors and earth located with the use of image location tapes (ILT) and stored in tapes known as TAT's, which are placed in a public archive (National Space Science Data Center). Next, the data are calibrated and remapped into evenly spaced cells across the swath and stored on tapes designated as CELL tapes. Four different cell sizes are used: $156 \times 156 \mathrm{~km}$ (all channels), $97.5 \times 97.5 \mathrm{~km}$ (all but $4.6-\mathrm{cm}$ channels), $60 \times 60 \mathrm{~km}(0.81-, 1.4-$, and $1.7-\mathrm{cm}$ channels), and $30 \times 30 \mathrm{~km}(0.81-\mathrm{cm}$ channels only). The purpose of the remapping is to permit proper multispectral retrievals of the geophysical parameters and to reduce the radiometric noise inherent in the instrument. These parameters, which include sea surface temperatures and near-surface wind speeds, atmospheric water vapor, sea ice concentration, sea ice age, the radiating temperature of the sea ice, and parameters related to snow cover, are stored on PARM (parameter) tapes by orbit. Finally, these parameters are remapped into standard map projections (MAP tapes) and displayed in colorformatted hard copy. The CELL's, PARM's, MAP's, and color images are also all archived for public use.

\section{Calibration}

Calibration of the SMMR data reported here consisted of the following elements: (1) conversion of the SMMR raw digital radiometric data into normalized counts $N$ in which the digitized signals received $C_{A}$ have been adjusted for radiometer gain variations by interpolation between counts obtained when observing the warm $C_{W}$ and cold $C_{c}$ references, i.e.,

$$
N=\left(C_{A}-C_{W}\right) /\left(C_{C}-C_{W}\right)
$$

(The warm and cold counts used are actually eight-scan running averages.); (2) conversion of normalized counts into absolute radiances by means of the relation

$$
T B(\mathrm{~K})=A+B^{*} N
$$

$A$ and $B$ are functions of the instrument temperatures and were deduced from laboratory measurements of the SMMR prior to launch; (3) correction for polarization mixing, taking into account an observed asymmetry about the center of scan [Gloersen et al., 1980]; (4) correction for the portion of the beams passing beyond the horizon into space, based on estimates of the beam patterns measured on an antenna range; and (5) remapping into the four different contiguous cell sizes placed orthogonal to the suborbital track described in the previous section. Not taken into account, at present, are calibration adjustments based on in-orbit observations of known targets and antenna pattern corrections other than for the spillover into space. All of these procedures are, to some extent, imperfect and result in biases in the brightness temperatures and the geophysical parameters calculated from them. The techniques for removing such biases vary with the given geophysical parameter and are discussed in the following sections.

\section{Sea Surface Temperatures}

Sea surface temperature (SST) is calculated from the observed radiances measured in seven of the ten SMMR channels. After determining that land is at least $600 \mathrm{~km}$ away and that no severe rainstorms are in the field of view (since these factors are known to affect adversely the accuracy of the retrieval), the following algorithm is applied:

$$
\begin{aligned}
& S S T(\mathrm{~K})=180+1.7^{*} 4.6 \mathrm{~V}-0.37^{*} 4.6 \mathrm{H} \\
& -326^{*} \ln (280-1.7 \mathrm{~V})-370^{*} \ln (280-1.7 \mathrm{H}) \\
& -11^{*} \ln (280-1.4 \mathrm{H})+56^{*}(285-2.8 \mathrm{H}) /(285-2.8 \mathrm{~V}) \\
& -245^{*}(285-1.7 \mathrm{H}) /(285-1.7 \mathrm{~V})-3.0^{*}(\text { inc.angle }) \\
& T=S S T-273.15+20 \\
& T^{\prime}=T-1.34-0.2^{*}\left(7.5-T^{*}\left(1-0.025^{*} T\right)\right)
\end{aligned}
$$

where the numbers with the $V$ 's and $H$ 's are values of calibrated radiance in degrees Kelvin for the wavelength $(\mathrm{cm})$ and polarization ( $H$ or $V$ ) indicated.

The rationale leading to $(3 a, b, c)$ is discussed in detail elsewhere [Wilheit et al., 1983] and is an improvement on retrieval techniques reported earlier [Wilheit and Chang, 1980; Wilheit, 1980] for use with the SMMR, based on experience gained from the SEASAT SMMR and early NIMBUS 7 SMMR data. Briefly, the major source of the SST information is the 4.6 $V$ channel, whereas the correction for windspeed information comes primarily from the $2.8 \mathrm{H}$ and $V$ channels, and the correction for atmospheric opacity is derived primarily from the $1.7 \mathrm{H}$ and $\mathrm{V}$ channels. The first equation is based entirely on models that were available before launch. Because of instrument calibration errors, retrievals using this equation have a large bias, which is corrected approximately by the second equation. The third equation then corrects for small variations in the emissivities of the surface that are nonlinear in temperature, again based on prelaunch models. The problems of time-varying calibration errors and imperfections in the radiative transfer model remain.

Great care must be exercised when comparisons are made between various SST data sets obtained by surface observations and SMMR-derived SST's. For instance an early attempt to compare SST's from unfiltered environmental data buoy and ocean stations data with nearly coincident SST's from SMMR led to very disappointing results. Part of this failure is attributed to occasional poor or even erroneous data in the surface observations, part to the fact that most of those observing platforms are within $600 \mathrm{~km}$ of land, and part to the making of some of the comparisons in regions of high horizontal gradients in the $S S T$, which clearly can lead to substan- 


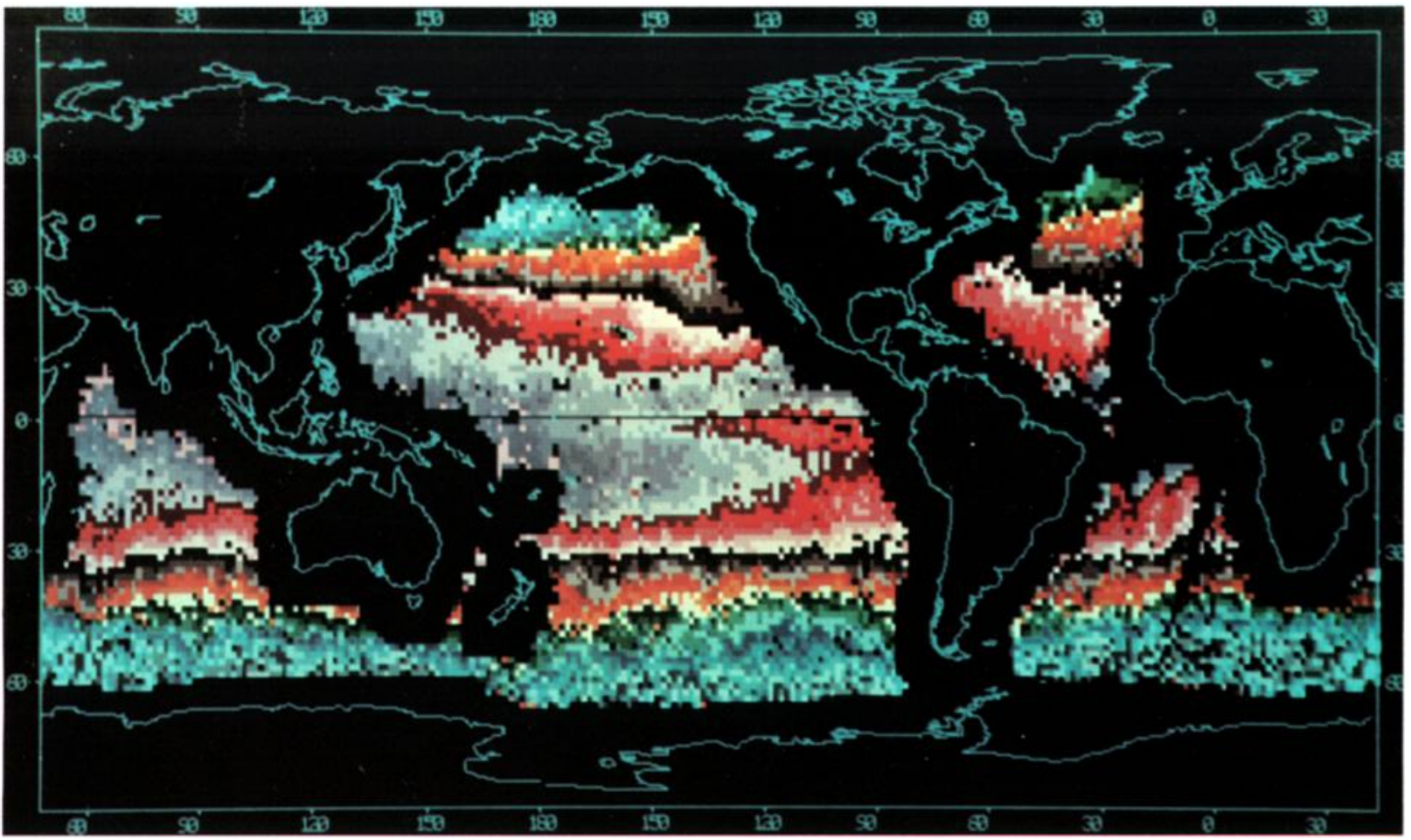

Plate 1. Global SST's from SMMR, June 1979.

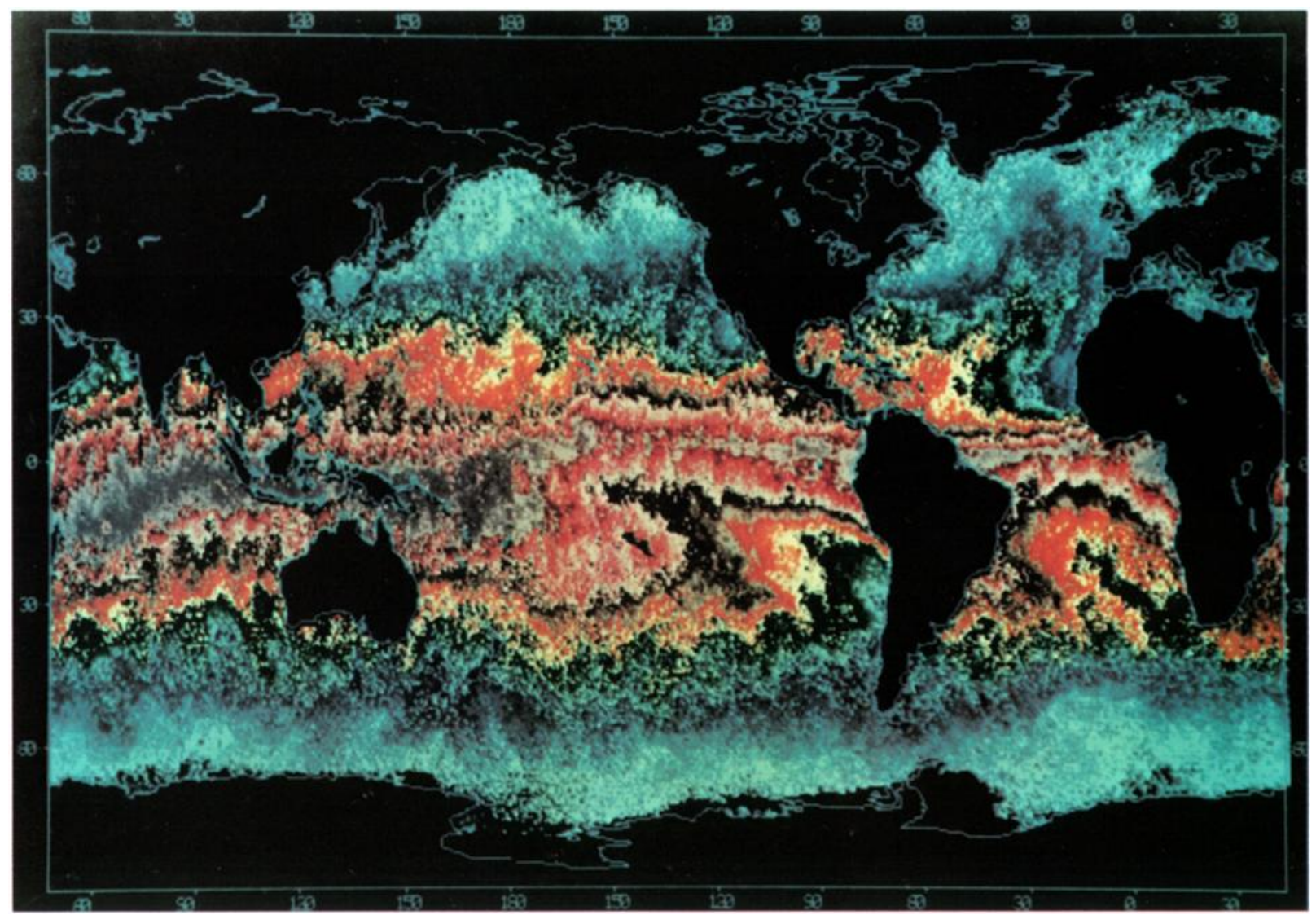

Plate 2. Global distribution of water vapor from SMMR, February 1979. 
TABLE 1. Comparison of SST's Obtained From SMMR and FGGE Data Buoys

\begin{tabular}{lccc}
\hline \multicolumn{1}{c}{ Month } & Bias, K & $\begin{array}{c}\text { Standard } \\
\text { Deviation, K }\end{array}$ & $\begin{array}{c}\text { Number of } \\
\text { Samples }\end{array}$ \\
\hline January & 0.7 & 1.73 & 895 \\
February/March & 1.0 & 1.65 & 1064 \\
May & 0.4 & 1.81 & 1608 \\
June & 0.4 & 1.74 & 1615 \\
Combined & 0.6 & 1.76 & 5182 \\
\hline
\end{tabular}

Southern hemisphere, 1979.

tial errors when comparing in situ measurements at points with remote measurements over $150 \mathrm{~km}^{2}$ areas. In order to overcome these difficulties a comparison was made with a well-filtered set of SST's from FGGE (First Global GARP Experiment) buoys in the southern hemisphere. The restrictions consisted of accepting only those SST's obtained at least $600 \mathrm{~km}$ from major land areas, that were within $5 \mathrm{~K}$ of WMO climatological values, and that occurred within 2 weeks and $100 \mathrm{~km}$ of the center of a corresponding 100-km SMMR cell. Comparisons were made only with nighttime data to avoid possible problems, including acquisition of the sun in the cold reference horn, large temperature differentials in the SMMR as it first enters sunlight, sunglint from the ocean surface, and possible ionospheric effects, all of which occur in the southern hemisphere in daytime.

So far, about 4 months worth of SMMR SST's bave been compared with nearby FGGE buoy data within the time period of January through June 1979. SMMR data averaged into $156 \times 156 \mathrm{~km}$ cells were used in $(3 a, b, c)$ to obtain the SST's compared with the FGGE data. The results of this comparison are given in Table 1. While a large bias (ca. $20 \mathrm{~K}$ ) exists between the FGGE and SMMR SST's obtained from $(3 a)$ (and removed in $(3 b)$ ), possibly reflecting a large bias in the SMMR calibration, only a $0.6 \mathrm{~K}$ peak-to-peak variation in this bias is observed over the four time periods studied (Table 1). Part of the 1.76-K standard deviation between the FGGE and SMMR SST's for the more than 4000 comparisons made in this 4-month data set is attributed to the errors inherent in the FGGE data, as noted below.

These errors can be reduced by additional temporal and spatial averaging of both the SMMR and surface observations of $S S T$ prior to the comparison. For example, an initial trial of this technique (R. L. Bernstein, private communication, $1981)$, using results from $(3 b)$, has yielded rms errors of $0.7 \mathrm{~K}$ upon averaging SST's from both mid-latitude ship and SMMR data sets into $200 \times 200 \mathrm{~km}$ bins for a 1-month time period and upon making minor adjustments in the offset and sensitivity of the SMMR-derived SST's. These results are illustrated in Figure 1. Similar results have been reported via use of SEASAT SMMR data [Bernstein and Morris, 1983]. A different study (using results from (3c)) in which only the SMMR $S S T$ 's were averaged into $200-\mathrm{km}$ cells and temporally smoothed with a four-sample Kalman filter resulted in the comparisons shown in Table 2. Here, both the FGGE and WMO climatology were treated as independent estimates of SST in these cells for the purpose of the three-way comparisons tabulated. The assumption of statistical independence among the errors in the three SST estimates permits a partition of the error between these three estimates. Since we are comparing fields over several hundred locations and have used only a single degree of freedom in adjusting the bias, the assumption of statistical independence is reasonable. The $1 \mathrm{~K}$ error for the buoy data represents the spatial variation between the point measurements provided by the buoys and the $100-\mathrm{km}$ scale of the other two measurements. Allowance for this source of error reduces the $1.76 \mathrm{~K}$ standard deviation shown in Table 1 to $1.45 \mathrm{~K}$ for the SMMR retrievals obtained directly from radiances aggregated into the $150-\mathrm{km}$ cells stored on the CELL tapes. The $0.9 \mathrm{~K}$ error for SMMR SST's is comparable to Bernstein's result, taking into account the smaller amount of temporal smoothing used.

A sample of the global view of SST's provided by SMMR is shown in Plate 1, where $S S T$ has been represented by 32 color steps of $1 \mathrm{~K}$ each. The SST's were obtained by averaging all of the retrievals made from June 1979 nighttime-only data. One can see the expected gross features of the SST field, such as the tongue of cold water in the eastern Pacific just south of the equator, presumably associated with the upwelling off Peru. In some of these data, cross-track variations in the SST's as a result of errors in the instrumental polarization mixing correction can be seen. It remains as a problem to be addressed.

A different technique has been used by Barbieri et al. [this issue] to produce higher-resolution localized maps of $S S T$ variations across ocean eddies.

\section{NeAR-SuRface Winds}

Early comparisons of near-surface wind speeds derived from SMMR with the NOAA environmental data buoys and ocean stations covering a latitude range of $26^{\circ} \mathrm{N}$ to $66^{\circ} \mathrm{N}$ and wind speeds up to $26 \mathrm{~m} / \mathrm{s}$ were somewhat encouraging. Although these retrievals required both a bias and slope adjustment, they did result in a $2.7 \mathrm{~m} / \mathrm{s}$ rms fit to the surface observations [Wilheit et al., 1983]. However, when they were compared with ship observations on a global scale, large positiondependent errors were found. Since these errors are not yet understood, the retrieval algorithm used is not presented here, nor will there be any near-surface wind retrievals included in the first-year archival products.

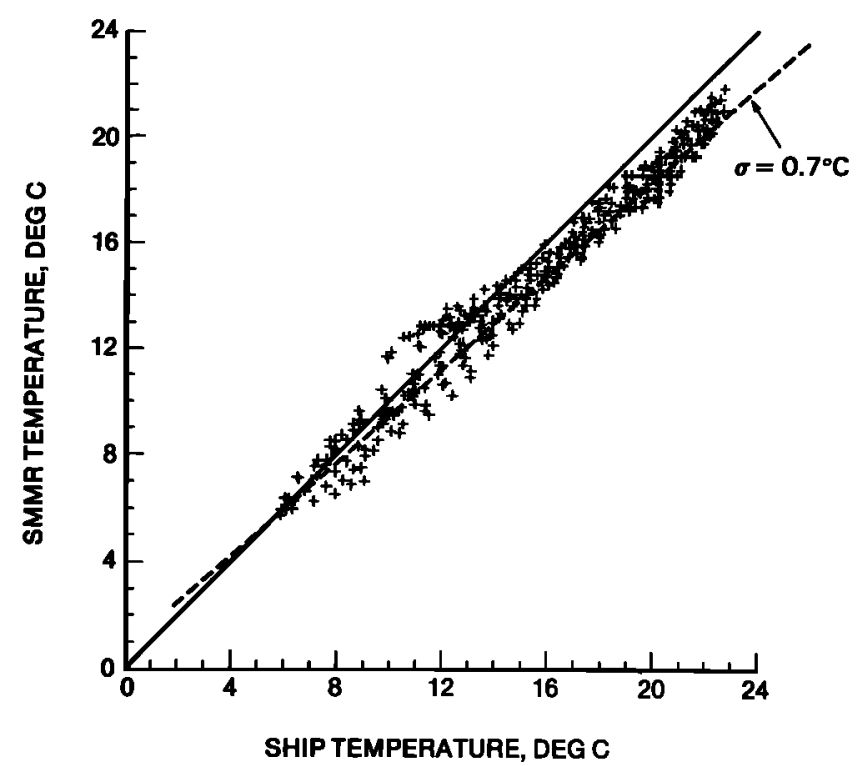

Fig. 1. Comparisons of averaged SST from ships and SMMR, February 15-March 9, 1979 (courtesy of R. L. Bernstein, Scripps Institution of Oceanography). 
TABLE 2. Comparisons With Smoothed SST's From SMMR Data

\begin{tabular}{|c|c|}
\hline Comparison & Standard Deviation \\
\hline $\begin{array}{l}\text { SMMR/FGGE } \\
\text { SMMR/Climatology } \\
\text { FGGE/Climatology }\end{array}$ & $\begin{array}{l}1.34 \mathrm{~K} \\
1.16 \mathrm{~K} \\
1.23 \mathrm{~K}\end{array}$ \\
\hline \multicolumn{2}{|c|}{ Implied Error Distribution } \\
\hline $\begin{array}{l}\text { SMMR } \\
\text { FGGE } \\
\text { Climatology }\end{array}$ & $\begin{array}{l}0.90 \mathrm{~K} \\
0.99 \mathrm{~K} \\
0.73 \mathrm{~K}\end{array}$ \\
\hline
\end{tabular}

Data from May and June 1979. Temporal smoothing, 1/2 month; spatial smoothing, $200 \mathrm{~km}$.

\section{ATMOSPHERIC WATER VAPOR}

Retrievals of oceanic water vapor $(W V)$ from microwave radiances are based on extensive experience with data from the multispectral microwave radiometers on board the NIMBUS 5 and NIMBUS 6 satellites [Staelin et al., 1976; Rosenkranz et al., 1978; Chang and Wilheit, 1980]. The algorithm is as follows:

$$
W V(\mathrm{~cm})=0.1085^{*}\left(20+v+0.011^{*} v^{*} v\right)-0.288
$$

where

$$
\begin{aligned}
v= & -0.405^{*}(1.7 H-105.5)-0.165^{*}(1.7 V-173.3) \\
& +0.489^{*}(1.4 H-139.8)+0.382^{*}(1.4 V-195.7) \\
& -0.225^{*}(0.8 H-141.0)+0.250^{*}(0.8 V-204.0)
\end{aligned}
$$

$W V$ is expressed as equivalent centimeters of water in a column. Comparisons of $W V$ data from radiosondes from selected stations have been used to obtain offset and sensitivity adjustments included in (5). The standard errors in the retrievals for $W V$ are $0.21 \mathrm{~cm}$ when compared with radiosonde data. A global display of average $\boldsymbol{W V}$ for February 1979 is shown in Plate 2. Rosenkranz [1982] has published highresolution maps of SMMR water vapor, $S S T$, and rainfall retrievals by using a different technique well suited to fronts and severe storms.

\section{Oceanic Rainfall Rates}

Comparisons of rain rate $R R$ obtained from SMMR data just off the Washington and Oregon coasts with coastal rain gage observations indicate that this parameter can be retrieved properly. The SMMR $R R$ values are obtained from brightness temperatures to which an $R R$ algorithm [Wilheit and Chang, 1980] has been applied. Figure 2 shows the National Meteorological Center analysis of the location of a surface cold front during a SMMR overpass on February 27, 1979, at 0104 GMT. Estimates of the speed and direction of the movement of the rain areas east of the front toward the coast permits comparison with the SMMR $R R$ for each $30 \times 30 \mathrm{~km}$ cell, with the mean rainfall averaged over the corresponding advection time past rain gages on the coast. The comparison is dependent on the assumptions that orographic effects are unimportant and that the rain-producing regions in the frontal zone do not change substantially during the advection time. Cold frontal rain bands are known to be quite persistent in this area. Rain bands in this particular front were followed by a radar on the coast for about $200 \mathrm{~km}$ [Hobbs and Persson, 1982]. The rain gage information was obtained from special high-resolution gages operated by the Cyclonic Extratropical Storms Project (CYCLES) and from climatological stations. Examples of comparisons within the first few hours after an overpass are seen in Table 3; these comparisons are described in detail elsewhere (K. B. Katsaros, unpublished manuscript, 1983). $R R$ derived from SMMR signals are generally lower than those inferred from rain gage records. We also found that SMMR misses isolated rain cells or very light rain occasionally. The general agreement at this stage of analysis is, however, encouraging, especially in view of the natural variability of precipitation. Because of the localized nature of these comparisons, it was deemed prudent not to archive $\boldsymbol{R} R$ retrievals on a global scale for the first-year data set.

\section{Sea ICE Parameters}

The multispectral radiances available from SMMR permit the estimation of several sea ice properties, including ice concentration $C$, which is the fractional area covered by first-year and multiyear sea ice; the fraction $F$ of ice that is multiyear; and the physical temperature of the ice $T_{\text {cee }}$. Tests of the pre-launch sea ice parameter retrieval algorithm [Gloersen et al., 1981] on data from the NIMBUS 7 SMMR led to a temperature-independent version. This latter technique [Cavalieri et al., this issue] uses multispectral radiance ratios rather than the absolute values of the radiances. Through the use of these ratios, the effect of variations in sea ice temperature is greatly reduced, significantly improving the accuracy of the $C$ and $F$ retrievals over single-channel retrievals [Gloersen et al., 1978] by the electrically scanning microwave radiometer on the NIMBUS 5 satellite (ESMR 5). The ratios utilized in this approach are the polarization $P R$ and spectral gradient ratio $G R$, defined as follows:
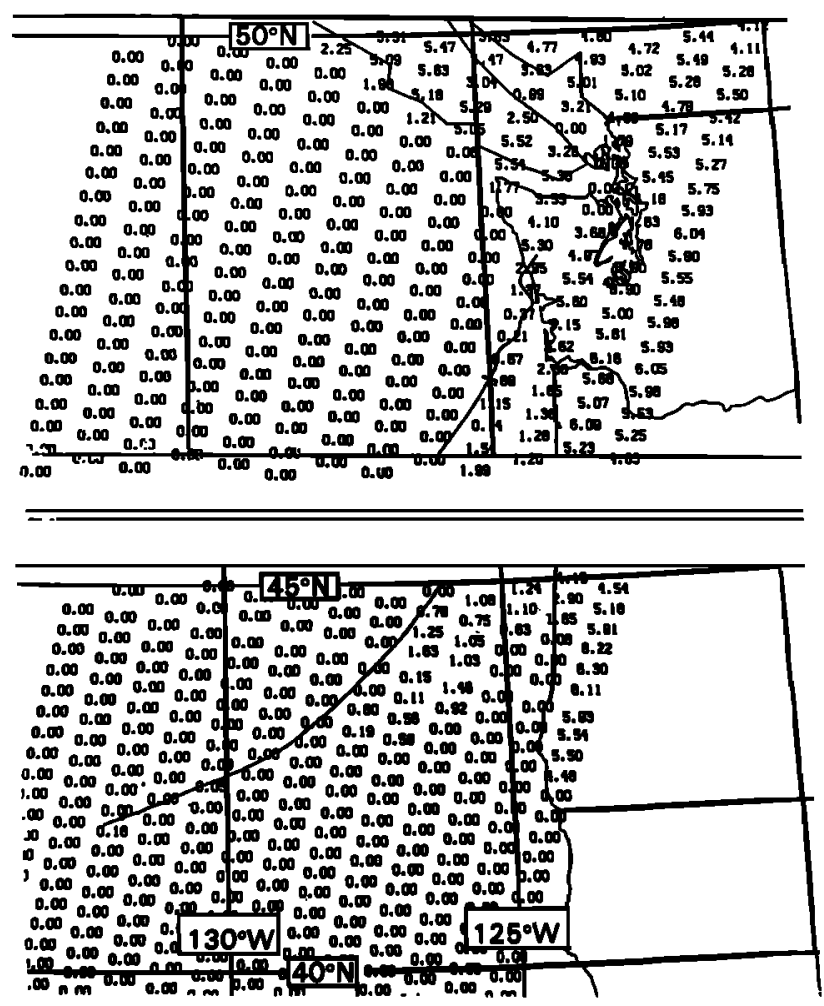

Fig. 2. Rain rates $(\mathrm{mm} / \mathrm{h})$ from $S M M R$ off the northwestern coast of USA, 0104 PST, February 27, 1979 (see also Table 3). A cold front is indicated by a solid line across the swath. Values appearing over land are meaningless in terms of rainfall and should be ignored. 


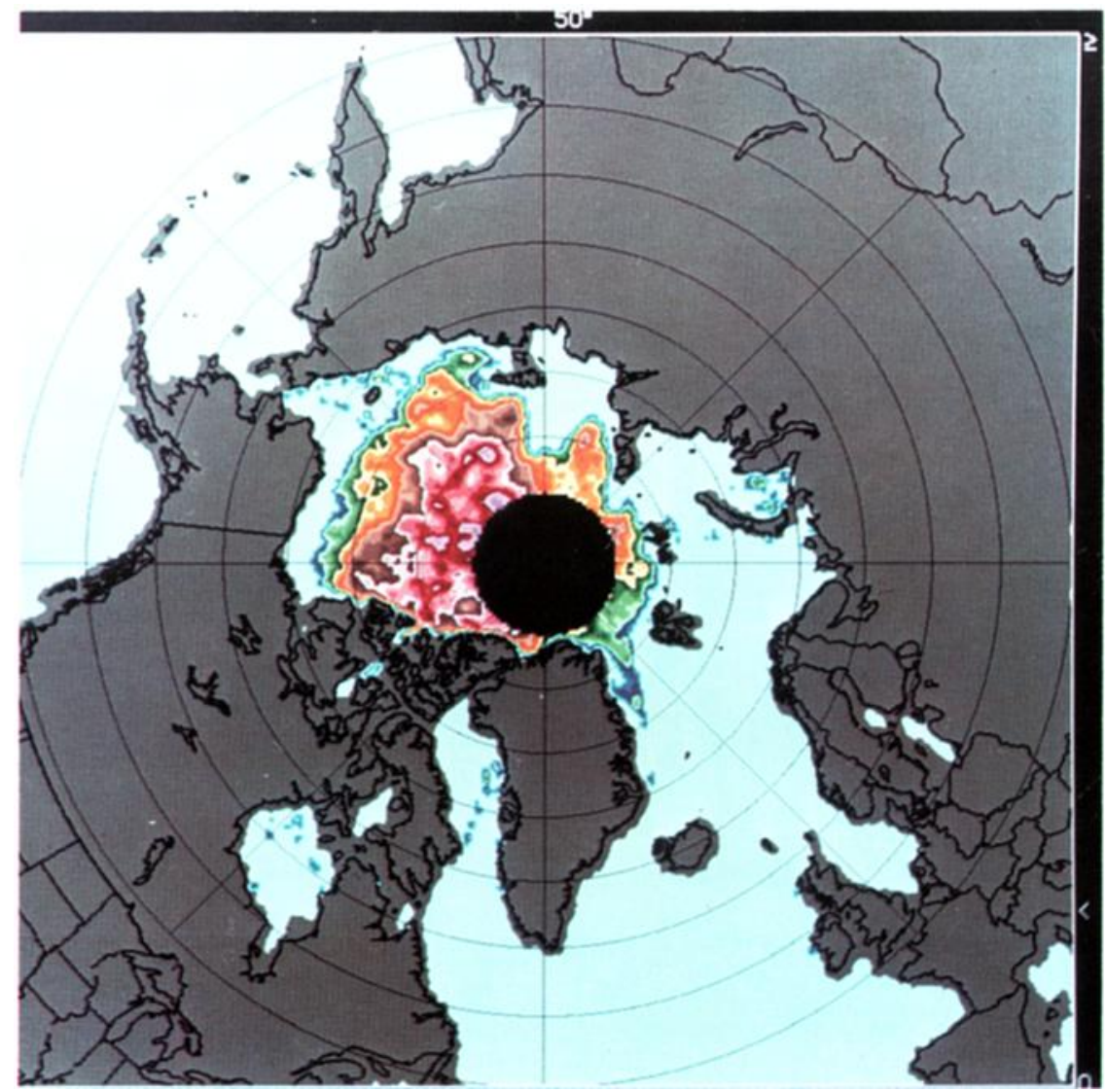

Plate 3 Sea ice concentration in the northern hemisphere, November 1-7, 1978.

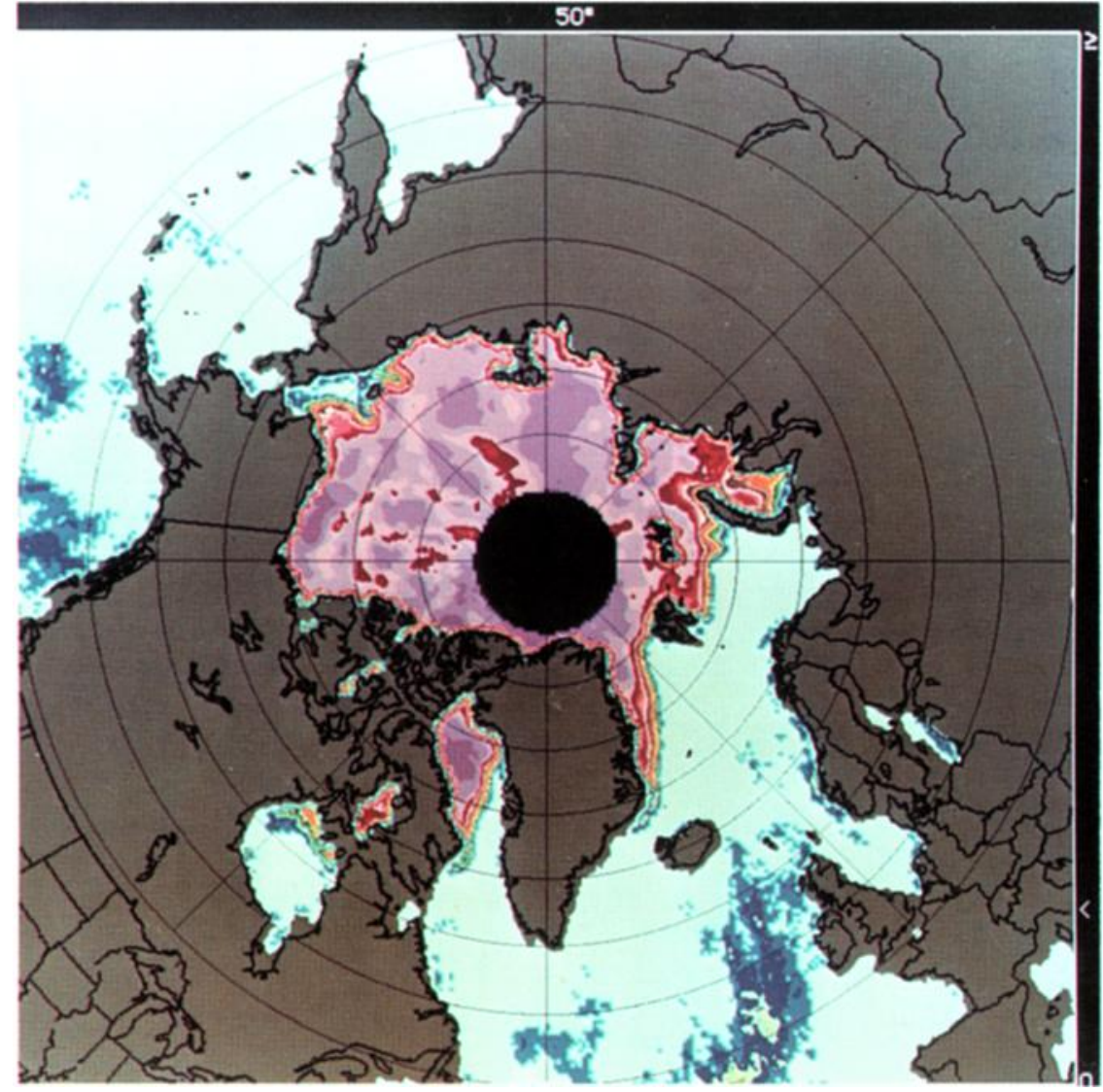

Plate 4 Distribution of multiyear ice in the northern hemisphere, November 1-7, 1978. 


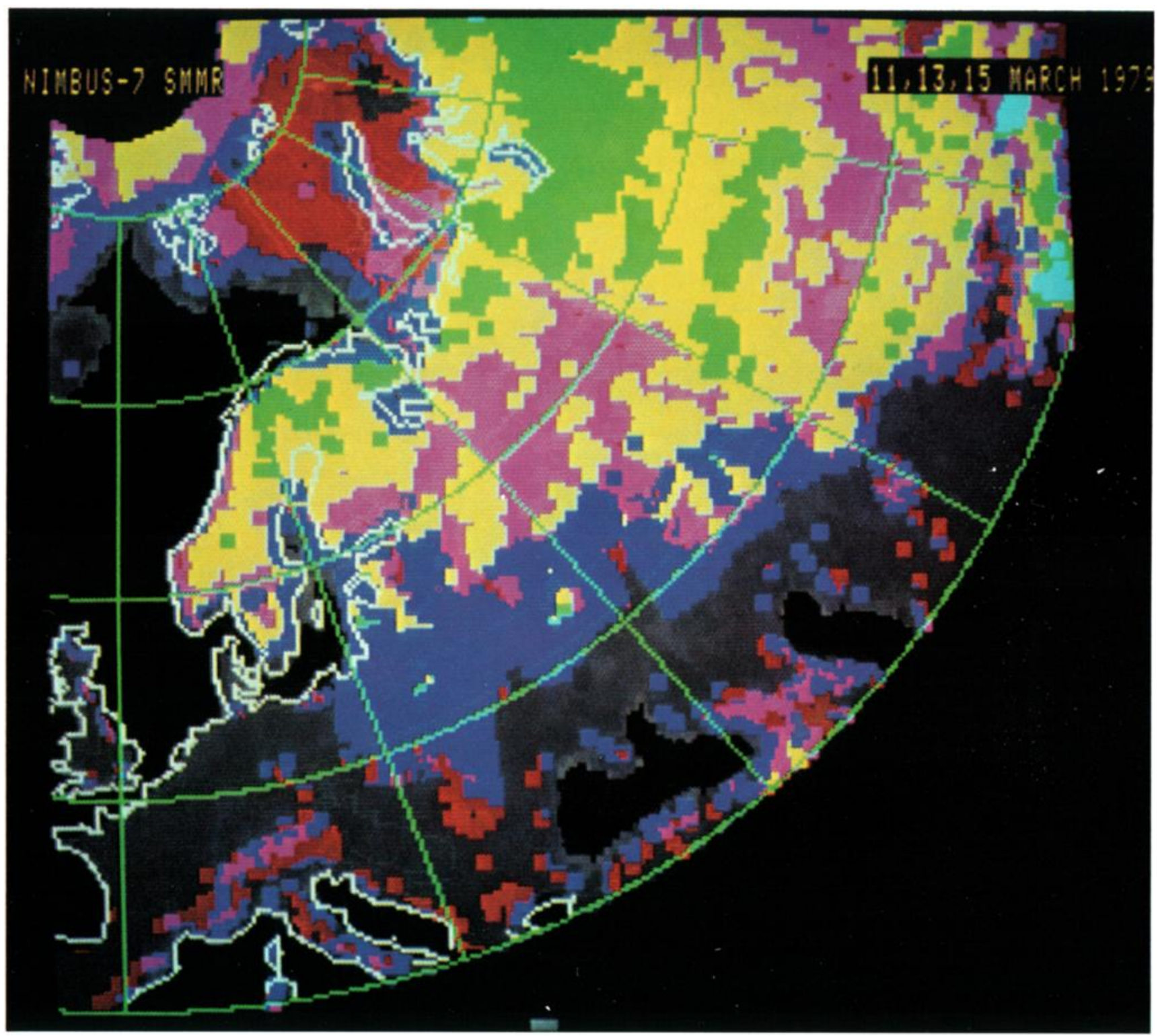

Plate 5. Snow distribution in the northern hemisphere. (Color display courtesy of H. Rott, University of Innsbruck, Austria.) The colors correspond to different values of the quantity $(0.81 \mathrm{H}-1.7 \mathrm{H})$ : cyan, $<-36 \mathrm{~K}$; green, -36 to -28 $\mathrm{K}$; yellow, -27 to $-18 \mathrm{~K}$; magenta, -17 to $-8 \mathrm{~K}$; red, -7 to $-1 \mathrm{~K}$; grey, $>0 \mathrm{~K}$ (no snow), and blue corresponds to rapid variations in $(0.81 H-1.7 H)$ with time, indicative of melting. 
TABLE 3. Rain Rates from SMMR at 0104 PST on February 27, 1979, and at 0032 PST on March 3, 1979, Compared to Average Rain Rates Observed at Coastal Rain Gages in a Subsequent Time Interval Corresponding to Arrival of the Air Mass in the Relevant SMMR Pixel

\begin{tabular}{llcc}
\hline \multicolumn{1}{c}{ Station } & Time, PST & SMMR, mm/h & Rain Gage, mm/h \\
\hline \multirow{3}{*}{ Quillayute } & \multicolumn{2}{c}{ February 27,1979} \\
& $1: 10-1: 40$ & 0.6 & \\
Moclips & $1: 40-3: 00$ & 0.0 & 0.8 \\
& $1: 40-2: 20$ & 0.0 & 0.6 \\
Pt. Brown & $2: 20-2: 50$ & 0.0 & 2.2 \\
& $1: 30-2: 10$ & 1.4 & 2.0 \\
Westport & $2: 10-2: 50$ & 0.0 & 4.2 \\
& $1: 40-2: 20$ & 0.9 & 2.5 \\
Long Beach & $2: 20-4: 00$ & 0.0 & $3-7$ \\
& $1: 30-2: 10$ & 1.8 & 1.7 \\
Astoria & $2: 10-3: 00$ & 0.5 & 2.0 \\
& $2: 00-2: 40$ & 2.3 & 4.5 \\
Nehalem & $2: 40-3: 20$ & 1.3 & 4.6 \\
& $1: 30-2: 10$ & 1.4 & 4.8 \\
& $2: 10-2: 50$ & 1.9 & 3.8 \\
Long Beach & $0: 30-3: 10$ & 0.0 & 3.8 \\
Astoria & $3: 10-4: 00$ & 0.2 & \\
& $1: 10-2: 30$ & 0.0 & 0.3 \\
Nahalem & $2: 30-3: 20$ & 0.3 & 0.4 \\
& $3: 20-4: 10$ & 0.5 & 0.4 \\
Yaquina Bay & $2: 00-2: 50$ & 1.0 & 0.6 \\
& $2: 50-3: 40$ & 1.3 & 0.8 \\
Bandon & $1: 00-1: 50$ & 1.3 & 1.0 \\
& $1: 50-2: 40$ & 2.4 & 1.0 \\
& $2: 40-3: 30$ & 2.7 & 2.0 \\
& $1: 15-2: 15$ & 2.0 & $4-5$ \\
& $2: 15-3: 00$ & 0.2 & 5.0 \\
& & & 0.0 \\
& & 0.0 \\
\hline
\end{tabular}

$$
\begin{gathered}
P R(1.7)=(1.7 V-1.7 H) /(1.7 H+1.7 V) \\
P R(0.81)=(0.81 V-0.81 H) /(0.81 V+0.81 H) \\
G R=(0.81 V-1.7 V) /(0.81 V+1.7 V)
\end{gathered}
$$

The $P R$ 's are used principally to obtain $C$, taking advantage of the low polarization of microwave radiation from sea ice compared to high values from open water. $G R$ is used to obtain $F$, utilizing the property of greater scattering in the freeboard portion of multiyear sea ice at shorter wavelengths. The vertical polarization components are chosen for $G R$ to minimize any effects of varying surface roughness within and between the $F Y$ and $M Y$ ice types. The expressions used are as follows:

$$
\begin{gathered}
C=\left(a 1+a 2^{*} P R\right) /\left(a \overline{3} 3+a 4^{*} P R\right) \\
F=\left(b 1+b 2^{*} G R\right) /\left(b 3+b 4^{*} G R\right) \\
T_{\text {ice }}=\left((4.6 V)-271^{*}(1-C)^{*} \operatorname{EOV}(4.6)\right) /\left(E F V(4.6)^{*} C\right)
\end{gathered}
$$

where $E O V$ and $E F V$ are emissivities of open water and $F Y$ sea ice, respectively, for the $4.6 V$ channel. The $a$ 's and $b$ 's depend primarily on the three radiances selected as tiepoints for the two ice types encountered and open water but also partly on $F$ and $C$, respectively. Therefore, equations (9) are solved iteratively using an initial value of 0.5 for $F$ on the first pass. Five iterations suffice to achieve asymptotic values for $C$ and $F$. The sea ice tiepoint radiances selected for $F Y$ and $M Y$ ice were in Baffin Bay and northwest of Greenland, respectively, during the first week of February 1979.

The open water tiepoint was obtained from a radiative transfer calculation in which oceanic winds of $7 \mathrm{~m} / \mathrm{s}$ and atmospheric water vapor of $0.2 \mathrm{~cm}$ in the column were used. Examples of $C$ and $F$ images on a global scale are shown in Plates 3 and 4. Generally, the low concentration areas in Plate 3 tend to be in the marginal ice zone, with an extensive area of low ice concentration in the Barents and Kara seas, between Svalbard and North Land $\left(22^{\circ} \mathrm{E}\right.$ to $\left.100^{\circ} \mathrm{E}\right)$ and in the Chukchi Sea. There is one notable area of low ice concentration centered at about $81^{\circ} \mathrm{N}, 160^{\circ} \mathrm{E}$, well into the interior of the ice pack. Similar areas of low ice concentration in the interior of the ice pack have been deduced from observations with the use of ESMR 5 [Campbell et al., 1983]. False indications of the presence of ice, as observed over open oceans at midlatitudes (Plate 3), are to be expected because of the radiation from thick, moist clouds, which are uncommon over sea ice.

Plate 4 illustrates what fraction of the ice shown in Plate 3 is multiyear. It was necessary to limit the retrievals of $F$ to regions for which $C$ is greater than $30 \%$ to insure proper values. The multiyear fraction has considerably more spatial variation than the corresponding total ice concentration. Allowing for some ice dynamics, the isopleth defined by the green/blue color boundary in Plate 4 defines roughly the minimum extent of the ice pack the previous summer. Thus, for instance, it can be seen that in the previous summer the passage for sea vessels from the points along the northern coast of Alaska, such as Prudhoe Bay, to the Bering Strait was open, an event which does not always occur annually. Another feature of interest is the tongue of multiyear ice along the northeast shoreline of Greenland, indicative of the large-scale transport of sea ice through the Fram Strait at the end of the transpolar drift stream. A discussion of the distribution of the total ice concentration and multiyear fraction is given by Cavalieri et al. [this issue].

The sea ice algorithm reported here has been checked for internal consistency by assuring that histograms of the entire set of sea ice parameters obtained to date fall within reasonable bounds and that the results are in agreement with observations made during the two principal NASA CV-990 airborne laboratory underflights devoted to sea ice. The sea ice concentration is mapped at two spatial resolutions: $60 \mathrm{~km}$, based primarily on the polarization at $1.7 \mathrm{~cm}$, and $30 \mathrm{~km}$, based on the $0.81-\mathrm{cm}$ polarization, with some sacrifice in precision. Examination of the histogram based on the $60-\mathrm{km}$ scale data for the entire north polar region [Cavalieri et al., this issue] characteristically shows an ice peak and an ocean peak. For a mid-winter month the ice peak is typically centered within $2 \%$ of the $100 \%$ concentration point, with a half width at half maximum of $5 \%$. The ocean peak is somewhat broader and tends to center at about $4 \%$, resulting from atmospheric and ocean surface roughness effects and the decision to tiepoint the ocean data at low average wind speeds (to match average conditions as postulated in polynyas). A similar analysis of a regional histogram of the multiyear fraction in the central Arctic yields an estimate of $13 \%$ in the relative accuracy of the multiyear fraction retrieval. However, an estimate of the overall relative accuracy is in the range of $13 \%-25 \%$ because of occasional observations of multiyear fractions of up to $25 \%$ in areas known to be free of multiyear ice [Cavalieri et al., this issue].

Calculations based on a radiative transfer model have also predicted an accuracy of approximately $5 \%$ for $C(50-\mathrm{km}$ scale), $15 \%$ for $F$, and $6 \mathrm{~K}$ for $T_{\text {ice. }}$. Some of the error in the $F$ retrievals results from not having taken into account the pres- 
ence of new or young $F Y$ ice without snow cover within the instrumental footprint in the current algorithm. Another likely source of error is larger-than-anticipated variations in the properties of the snow cover on the sea ice, which has been presumed to average $15 \mathrm{~cm}$ in depth with little variation and to have a grain size of $0.2 \mathrm{~mm}$. Since the sea ice emissivities are known to change significantly in the polar melting seasons, this algorithm is not expected to function properly at such times. In fact, concentration retrievals in the area and for the period of the NORSEX (Norwegian Remote Sensing Experiment) expedition in September-November 1979 [NORSEX Group, 1983; Svendsen et al., 1983], when temperatures are still near the melting point, had maximum values of about $80 \%$ that were up to $20 \%$ lower than those obtained from surface and aircraft observations and from an alternative algorithm reported by Svendsen et al. [1983]. Later in the winter this same area yields a more reasonable distribution of concentrations, with values up to $100 \%$. More detailed validation studies of this algorithm are currently underway and should provide a better estimate of the accuracy of the retrieved sea ice parameters. Perhaps these studies will also lead to an algorithm improvement that will permit including areas near the melting point of ice.

Other early results indicate that a sharp sea ice edge can be located within $10 \mathrm{~km}$ [NORSEX Group, 1983; Svendsen et al., 1983] and that temporal and spatial changes in $C$ can be observed on a 30-km scale [Cavalieri et al., 1983]. A quite unexpected result, in view of the limited spatial resolution attainable with the SMMR data, was the ability to track a distinct patch of multiyear ice (about $100 \mathrm{~km}$ in extent) as it drifted into the Fram Strait on its way from Svalbard to Greenland [Svendsen et al., 1983] over a 24-day period during the Norwegian Remote Sensing Experiment.

\section{SnOW Field Parameters}

Earlier investigations of snow, using microwave radiometry, have shown that important snow cover parameters, such as areal extent, water equivalent [Edgerton et al., 1971; Hofer and Maetzler, 1980; Ulaby and Stiles, 1980; Chang et al., 1982] and onset of melt [Edgerton et al., 1971; Chang and Gloersen, 1975; Schanda and Hofer, 1977; Stiles and Ulaby, 1980] can be derived from microwave signatures of a snow field. These snow parameters are of great importance in climatology and weather forcasting and also have applications in hydrology, e.g., runnoff prediction. Northern hemisphere snow maps are presently produced by the National Earth Satellite Service (NESS) and the U.S. Air Force Global Weather Center (AFGWC), making use of spaceborne visible and infrared data and, if available, ground observations. For small-scale studies, LANDSAT imagery and a priori knowledge of a given watershed can be used to obtain information on snow water equivalent [Rango and Itten, 1979]. The accuracy of the global snow maps has been reviewed by Kukla and Robinson [1981]. They found that the fine structure of the snowline (border between snow and no snow) is not reproduced accurately and that fast variations in snow extent are frequently missed as a result of persistent cloudiness.

Microwave experiments on board NIMBUS 5 and 6 have been used to produce snow cover maps with data of the NIMBUS E microwave spectrometer (NEMS) [Kunzi and Staelin, 1975] and the scanning microwave spectrometer (SCAMS) [Fisher et al., 1976] and to obtain information on snow water equivalent by using data from the electrical scanning micro- wave radiometers (ESMR) [Foster et al., 1980]. These earlier observations were hampered by poor spatial resolution (NEMS and SCAMS) or single-frequency data (ESMR).

From a careful study of SMMR data over test areas in Finland, southern Russia, and the prairies of the USA and Canada, we have shown that the three snow cover parameters extent, water equivalent ( $S W E$ ), and onset of melting can be retrieved [Kunzi et al., 1982]. All derived algorithms for snow cover parameters make use of the $0.81-\mathrm{cm}$ and $1.7-\mathrm{cm}$ channels only; additional SMMR channels do not substantially improve the retrieval. For snow extent the following relation is used to answer the question, "Is there snow?": If

$$
(0.81 H-1.7 H) \leqq-0.5 \mathrm{~K}
$$

then yes; if

$$
(0.81 H-1.7 H>-0.5 \mathrm{~K}
$$

then no. The quantity $0.5 \mathrm{~K}$ was determined empirically by comparing the surface observations of the test areas with the SMMR data. The threshold of detectability for a dry snow layer is about $5 \mathrm{~cm}$.

For SWE determination, approximately 400 comparisons have been made between accurate ground observations and SMMR-SWE in all test areas. This results in the following equation for SWE:

$$
S W E=-0.385^{*}(0.81 \mathrm{H}-1.7 \mathrm{H})+1.94 \quad\left(\mathrm{~g} / \mathrm{cm}^{2}\right)
$$

The retrieval accuracy is $2 \mathrm{~g} / \mathrm{cm}^{2} S W E$ for snow layers of $<50$ $\mathrm{cm}$; this value meets the baseline requirement given in the NASA Climate Plan for this parameter. However, we have found that for very different climatic regions, such as Siberia and northern Canada, the algorithm needs to be adjusted. At present, we conclude that $S W E$ can only be retrieved on a regional basis.

The onset of snow melt can easily be detected by a temporal analysis of the SMMR data by observing the characteristic changes of the brightness temperature $T B$ for a wet snow pack, approximating a blackbody, and a refrozen snow layer (decreasing $T B$ for increasing frequency). The different snow parameters are displayed in Plate 5. The range of the quantity $(0.81 H-1.7 H)$ is displayed in different colors from cyan to red. Using (11), a rough estimate of the snow water equivalent can be made. Snow-free areas are grey, and melting is shown in blue. Black areas indicate open water or missing data.

A SMMR-like instrument offers itself for operational snow cover parameter retrieval because the algorithms are simple and suited for automated systems. The retrieved parameters are more accurate than those obtained from existing operational sensors, and it is possible to obtain valuable information for hydrology on $S W E$ and melting where no other sensors allow equally accurate estimations.

\section{CONCLUDing Remarks}

Present indications are that the NIMBUS 7 SMMR will achieve its proposed goals of nearly all-weather capability in determining various oceanic, atmospheric, cryospheric, and terrestrial parameters of practical and scientific interest. The first-year data set is available for weather, climate, oceanic, and hydrologic process studies. It is archived at the National Space Science Data Center, Code 601, NASA Goddard Space Flight Center.

Acknowledgment. Major support for this study was provided through the auspices of the Nimbus Project Office. 


\section{REFERENCES}

Barbieri, R., A. T. C. Chang, P. Gloersen, and J. A. Kogut, Comparative study of a Gulf Stream eddy using satellite based microwave and infrared radiometers, J. Geophys. Res., this issue.

Bernstein, R. L., and J. H. Morris, Tropical and mid-latitude North Pacific sea surface temperature variability from the Seasat SMMR, J. Geophys. Res., 88, 1877-1891, 1983.

Campbell, W. J., P. Gloersen, and J. H. Zwally, Aspects of Arctic sea ice observable by sequential passive microwave observations from space, in Arctic Technology and Policy: An Assessment and Review for the Next Decade, edited by I. Dyer and C. Chrysostomidis, pp. 199-222, Hemisphere Publishing Corporation, New York, 1983.

Cavalieri, D. J., P. Gloersen, and W. J. Campbell, Determination of sea ice parameters with the NIMBUS 7 SMMR, J. Geophys. Res, this issue.

Cavalieri, D. J., S. Martin, and P. Gloersen, NIMBUS 7 SMMR observations of the Bearing Sea ice cover during March 1979, J. Geophys. Res., 88, 2743-2754, 1983.

Chang, T. C., and P. Gloersen, Microwave emission from ice and wet snow, Proceedings of a Workshop on Operational Applications of Satellite Snowcover Observations, NASA SP-391, pp. 399-407, NASA, Washington, D.C., 1975.

Chang, A. T. C., and T. T. Wilheit, Remote sensing of water vapor, liquid water, and wind speed at the ocean surface by passive microwave techniques from the Nimbus 5 satellite, Radio Sci., 14, 793802, 1979.

Chang, A. T. C., J. L. Foster, D. K. Hall, A. Rango, and B. K. Hartline, Snow Water Equivalent Estimation by Microwave Radiometry, Cold Reg. Sci. Technol., 5, 259-267, 1982.

Edgerton, A. T., A. Stogryn, G. Poe, Microwave Radiometric Investigations of Snow Packs, Final Rep. 1258R-4, Contract IA-08-00111828 , U.S. Geol. Surv., Reston, Va., 1971.

Fisher, A. D., B. L. Ledsham, P. W. Rosenkranz, and D. H. Staelin, Satellite observations of snow and ice with an imaging passive microwave spectrometer, paper presented at Symposium on Metereological Observations from Space: Their Contribution to the First GARP Global Experiment, 19th meeting of COSPAR, Philadelphia, Pa., June 8-10, 1976.

Foster, J. L., A. Rango, D. K. Hall, A. T. C. Chang, L. J. Allison, and B. C. Diesen III, Snowpack monitoring in North America and Eurasia using passive microwave satellite data, Remote Sensing Environ., 10, 285-298, 1980.

Gloersen, P., and F. T. Barath, A scanning multichannel microwave radiometer for Nimbus-G and SEASAT-A, IEEE J. Oceanic Eng., $O E-2,172-178,1977$.

Gloersen, P., W. Nordberg, T. J. Schmugge, T. T. Wilheit, and W. J. Campbell, Microwave signatures of first-year and multiyear sea ice, J. Geophys. Res., 78, 3564-3572, 1973.

Gloersen, P., H. J. Zwally, A. T. C. Chang, D. K. Hall, W. J. Campbell, and $R$. $O$. Ramseier, Time-dependence for sea-ice concentration and multiyear ice fraction in the Arctic Basin, BoundaryLayer Meteorol., 13, 339-359, 1978.

Gloersen, P., D. J. Cavalieri, and H. V. Soule, An alternative algorithm for correction of the scanning multichannel microwave radiometer polarization radiances using Nimbus-7 observed data, NASA Tech. Memo. 80672, 1980.

Gloersen, P., D. J. Cavalieri, and W. J. Campbell, Derivation of sea ice concentration, age, and surface temperature from multispectral microwave radiances obtained with the Nimbus-7 scanning multichannel radiometer, in Oceanography from Space, edited by J. R. F. Gower, pp. 823-829, Plenum, New York, 1981.

Hobbs, P. V., and P. O. G. Persson, The mesoscale and microscale structure and organization of clouds and precipitation in midlatitude cyclones, 5 , The substructure of narrow cold-frontal rainbands, J. Atmos. Sci., 39, 280-295, 1982.

Hofer, R., and C. Maetzler, Investigations on snow parameters by radiometry in the 3- to $60-\mathrm{mm}$ wavelength region, J. Geophys. Res., $85,453-460,1980$.

Hollinger, J. P., Passive microwave measurements of sea surface roughness, IEEE Trans. Geosci. Electron., GE-9, 169, 1971.

Kukla, G., and D. Robinson, Accuracy of operational snow and ice charts, paper presented at IEEE International Geoscience and Remote Sensing Symposium, Washington, D.C., June 8-10, 1981.

Kunzi, K. F., and D. H. Staelin, Measurements of snow cover over land with the Nimbus- 5 microwave spectrometer, paper presented at Tenth International Symposium on Remote Sensing of Environment, Univ. Mich. Willow Run Lab., Ann Arbor, Mich., October 6-10, 1975

Kunzi, K. F., S. Patil, H. Rott, Snow cover parameters retrieved from Nimbus-7 scanning multichannel microwave radiometer (SMMR) data, IEEE Trans. Geosci. Remote Sensing, GE-20, 452-467, 1982.

NORSEX Group, The Norwegian Remote Sensing Experiment (NORSEX) in a marginal ice zone, Science, 220, 781-787, 1983.

Rango, A., and K. I. Itten, Satellite potentials in snow cover monitoring and runoff prediction, Nordic Hydrol., 7, 209-230, 1976.

Rosenkranz, P. W., Inversion of data from diffraction-limited multiwavelength remote sensors, 3, Scanning multichannel microwave data, Radio Sci., 17, 257-267, 1982.

Rosenkranz, P. W., D. H. Staelin, and N. C. Grody, Typhoon June (1975) viewed by a scanning microwave spectrometer, J. Geophys. Res., 83(C4), 1857-1868, 1978.

Schanda, E., and R. Hofer, Microwave multispectral investigations of snow, paper presented at Eleventh International Symposium on Remote Sensing of Environment, sponsor, Ann Arbor, Mich., April 25-29, 1977.

Staelin, D. H., K. F. Kunzi, R. L. Pettyjohn, R. K. L. Poon, R. W. Wilcox, and $\mathbf{J} \mathbf{W}$. Waters, Remote sensing of atmospheric water vapor and liquid water with the Nimbus-5 microwave spectrometer, J. Appl. Meteorol., 15(11), 1204-1214, 1976.

Stiles, W. H., and F. T. Ulaby, The active and passive microwave response to snow parameters, 1 , Wetness, J. Geophys. Res., 85, $1037-1044,1980$.

Svendsen, E., K. Kloster, B. Farrelly, O. M. Johannessen, J. Johannessen, W. J. Campbell, P. Gloersen, D. Cavalieri, and C. Maetzler, Norwegian Remote Sensing Experiment: Evaluation of the NIMBUS 7 scanning multichannel microwave radiometer for sea ice research, J. Geophys. Res., 88, 2781-2792, 1983.

Ulaby, F. T., and W. H. Stiles, The active and passive microwave response to snow parameters, 2, Water equivalent of dry snow, $J$. Geophys. Res., 85, 1045-1049, 1980.

Wilheit, T. T., Microwave determination of oceanographic and meteorological parameters, COSPAR Space Res., 20, 15-20, 1980.

Wilheit, T. T., and A. T. C. Chang, An algorithm for the retrieval of ocean surface and atmospheric parameters from the observations of the SMMR, Radio Sci., 15, 525-544, 1980.

Wilheit, T. T., J. Greaves, J. Gatlin, D. Han, B. M. Krupp, and A. S. Milman, Retrieval of Ocean Surface Parameters from the Scanning Multichannel Microwave Radiometer on the Nimbus-7 Satellite, IEEE Trans. Geosci. Remote Sensing, in press, 1983.

F. T. Barath, California Institute of Technology, Jet Propulsion Laboratory, Pasadena, CA 91103.

W. J. Campbell, USGS Ice Dynamics Project, University of Puget Sound, Tacoma, WA 98416.

D. J. Cavalieri, P. Gloersen, and T. T. Wilheit, Goddard Laboratory for Atmospheric Sciences, NASA/Goddard Space Flight Center, Greenbelt, MD 20771.

A. T. C. Chang, Earth Survey Applications Division, NASA/Goddard Space Flight Center, Greenbelt, MD 20771.

P. Gudmandsen, Electromagnetics Institute, Technical University of Denmark, DK-2800, Lyngby, Denmark.

O. M. Johannessen, Geophysical Institute, University of Bergen, N-5014, Bergen, Norway.

K. B. Katsaros, Department of Atmospheric Sciences, University of Washington, Seattle, WA 98195

K. F. Kunzi, University of Bern, CH-3012 Bern, Switzerland.

E. Langham, RADARSAT Project Office, Ottawa, Ontario K1P 5M9, Canada.

R. O. Ramseier, Atmospheric Environment Service, Ottawa, Ontario K1A OH3, Canada.

D. B. Ross, NOAA Sea-Air Interaction Laboratory, Miami, FL 33149 .

D. Staelin, Research Laboratory of Electronics, Massachusetts Institute of Technology, Cambridge MA 02139.

E. P. L. Windsor, Dynamics Group, British Aerospace, Bristol BS12 7QW, England.

(Received February 2, 1983;

revised August 29, 1983;

accepted September 26, 1983.) 